\title{
Fighting stressful situations from the viewpoint of emotional competence
}

\author{
Milena Svetlin \\ ÂME SAINE, studio za harmonijo čutenj, Milena Svetlin s.p. zakonska in družinska terapija, \\ Savska cesta I3B, I230 Domžale, Slovenija \\ milena.svetlin@gmail.com
}

\begin{abstract}
Introduction: Stress is an important factor in daily life, affecting individual's health. It is organism's response to different inner and external factors. The degree to which an individual is capable of dealing with stressful situations is also related to his ability of emotional processing. Emotional competence shows the way a person understands emotions in a certain developmental period, the way he expresses, communicates and integrates them into his self-perception. The aim of our research project was to ascertain the impact of emotional competence upon individual's strategy of dealing with stressful situations. Methods: We performed a quantitative research. Regarding the calculation of the mutual dependence of degrees of emotional competence (based on the Emotional competence questionnaire) and stress handling strategies (Brief COPE questionnaire), we checked the conditions for the calculation of correlation coefficients and applied Spearman's rho for the bivariate correlation analysis. The analysis included data on 289 participants. Results: According to the research results every subdimension of emotional competence is related to at least four strategies of stress handling in a statistically significant measure. Correlation between variables is weak $(\mathrm{r}=0.154)$, at the level of $1 \%$ risk, to strong $(\mathrm{r}=0.589)$, at the level of $5 \%$ risk. Discussion: Acquisition of emotional competence is a factor affecting the choice of functional strategies of stress handling. Lifelong progress leads to a better emotional condition, which, in turn, sustains active population with the ability of creative performance in the business field, as well as with the feeling of living a full life in private sphere.

Key words: stress, stress handling, emotional competence, emotional condition
\end{abstract}




\section{Theoretical Framework}

Coping with stress is an everyday thing, playing important role in the physical and psychological well-being of a person (Carver, Scheier in Weintraub 1989). Stress is defined as physical response to life situations, as a reaction to physical threats of environment. It is the inner, conditioned reaction of individual to the perceived external pressures, manifested in the form of fight or flight. The individual's choice of stress handling strategy depends on his dealing with stressful situations and its impact on his health (van Heck in de Ridder 2001).

Emotions play key role in individual's life, representing a significant part in the diversity of everyday life: in the experience of self, mutual relations, workplace, creative processes, sports, etc. (Cvetek 2014, 5). Theories of lifelong emotional development are a relative novelty in the field of psychology of emotions. So far two theories of functional emotional development are known. The first theory is an internalized model of emotional development and emotional ㅇ regulation by Holodynski and Fridlmeier, focusing mostly on the management of emotions competence. The second theory is Greenspan's theory of functional emotional development, which is somewhat wider and related to the development of self, consciousness and thinking. Greenspan promoted the idea of the higher mental competences (logical thinking and the use of symbols) basically resulting from the transformation of affect, meaning that development of these competences is in fact based on the prior emotional development (Cvetek 2014, 95). According to Greenspan's theory sequence of periods in emotional development cannot be skipped, every developmental competence comprising all the prior ones (Greenspan 1989). If a person fails to develop earlier emotional competences not all is lost for him yet; it just means this person has to make a conscious effort of returning to the lower developmental grade. Only when the individual manages to develop the lacking comptence can he develop or perfect the following one. According to Greenspan (Cvetek 2014, 95 - 167), the competences are: emotional steadiness and interest in the world, intimate connectedness to others, mutual deliberate exchange, mutual social problem solving, use of symbolic imagery, emotional logical thinking, comparative emotional thinking, differentiation of emotional nuances, reflective emotional thinking, consideration of the unconscious, contemplating one's future, inner emotional autonomy, intimate commitment, responsible care for other people and emotional parenthood, care for the wider social community, universal love and wisdom (Carver, Scheier in Weintraub 1989).

\section{The Present Study}

The purpose of our research study was to ascertain the impact of emotional competences upon individual's stress coping strategies. We posed the following research question: » How dimensions of emotional competences correlate with the utilisation of coping strategies? 


\section{Methods}

\section{Participants}

There were 289 participants in the research project $(M=40.24$ years, $S D=10.9$, $\min =19, \max =72), 30$ or $10.4 \%$ of these were males $(M=40.2$ years, $S D=11.2$, $\min =19, \max =72)$ and $259 \mathrm{oz} .89 .6 \%$ females $(M=39.8$ years, $S D=10.8, \min =19$, $\operatorname{Max}=69) .34(11.8 \%)$ of the participants were single, $114(39.4 \%)$ were married, $80(27.7 \%)$ were not married but had a long-lasting relationship, 7 (2.4\%) were in the process of divorce, 35 (12.1\%) were divorced, 14 (4.8\%) were divorced and in a new relationship, 5 (1.7\%) were widowed. 1 (0.3\%) participant had primary education, 15 (5.3\%) participants had vocational training, 55 (19\%) had secondary education, $84(29.1 \%)$ had higher, university education or Bologna first level education, $100(34.6 \%)$ had university or Bologna second level education, 31 (10.7\%) had specialization or master's degree, and 3 (1\%) participants had doctor's degree. $37(12.8 \%)$ participants were from the Gorenjska region, 11 (3.8\&\%) were from the Goriška region, 10 (3.5\%) were from the South-Eastern part of Slovenia, 7 (2.4\%) were from the Karst region, 14 (4.8\%) were from the Karst-Coastal region, 148 (51.2\%) were from the Central Slovenia, 17 (5.9\%) were from Podravje, 11 (3.8\%) from Pomurje, 16 (5.5\%) from Savinjska region, 8 (2.8\%) from srednjePosavje and 7 (2.4\%) participants were from Zasavje region.

\section{Measures}

Questionnaire of emotional competence of the author Associate Prof. Mateja Cvetek, Ph.D. is a self-assessment questionnaire assessing the developmental degree of one's emotional competence. The questionnaire is divided into 8 dimensions: Trust into partner (Cronbach alpha=0.730) (eg.: »When me and my partner are faced with a conflict ... I know who to ask for help.«), Mutuality and cooperation between partners (Cronbach alpha=0.940) (eg.: "When me and my partner are faced with a conflict ... I feel we are emotionally close.«), Understanding and verbal expression of emotions (Cronbach alpha $=0.757)($ eg.: $»$ When me and my partner are faced with a conflict ... I cannot find words to express my feelings.«), Comparative emotional reasoning (Cronbach alpha=0.785) (eg.: »When me and my partner are faced with a conflict ... I can foresee the impact of emotions.«), Emotional oscillations (Cronbach alpha=0.80o) (eg.: »When me and my partner are faced with a conflict ... my emotions are of diverse intensity: from weak to very strong.«), Autonomous search for new options Cronbach alpha=0.786) (eg.: »When me and my partner are faced with a conflict ... I try to learn a lesson from the conflicting situation.«), Autonomous wish for self-improvement (Cronbach alpha $=0.729$ ) (eg.: »When me and my partner are faced with a conflict ... I strive to improve my conflict management approach.«), Autonomy of judgement (Cronbach alpha=0.841) (eg.: »When me and my partner are faced with a conflict ... I have the feeling of being capable of autonomous decision-making.«). The participants used a 5-grade scale for assessing the statements, i.e.: 1- almost never applies to me (from o\% to 10\%), 2 - applies to me rarely ever (from $110 \%$ to $35 \%$ ), 3- 
applies to me sometimes (from $36 \%$ to 65\%), 4 - applies to me frequently (from $66 \%$ to $90 \%$ ), 5 - applies to me almost always (from $91 \%$ to $100 \%$ ).

Brif COPE is a shortened version of the questionnary COPE Inventory (Carver, Scheier in Weintraub 1989); it is a multidimensional self-assessment questionnaire for measuring functionality of stress coping responses. The questionnaire is divided into thirteen dimensions: Self-distraction (eg.: » I've been turning to work or other activities to take my mind off things.«), Active coping (eg.: »I've been concentrating my efforts on doing something about the situation I’m in.«), Denial (eg.: »I’ve been saying to myself “this isn't real.«), Substance use (eg.: »I've been using alcohol or other drugs to make myself feel better.«), Use of emotional support (eg.: »I've been getting emotional support from others.«), Use of instrumental support (eg.: »I've been getting help and advice from other people.«), Behavioral disengagement (eg.: »I've been giving up trying to deal with it. «), Venting (eg.: »I've been saying things to let my unpleasant feelings escape.«), Positive reframing (eg.: »I’ve been trying to see it in a different light, to make it seem more positive. «), Planning (eg.: »I’ve been trying to come up with a strategy about what to do.«), Humour (eg.: »I've been making jokes about it.«), Acceptance (eg.: »I've been accepting the reality of the fact that it has happened.«), Religion (eg.: »I’ve been trying to find comfort in my religion or spiritual beliefs.«) and Self-blame (eg.: I’ve been criticizing myself.«). The participants used 4-grade scale for assessment. i.e.: 1- I haven't been doing this at all , 2 - I've been doing this a little bit , 3 -I've been doing this a medium amount, 4 - I've been doing this a lot.

\section{Procedure}

The questionnaire was published on website links, accessible to a vast number of internet users. The Brif COPE questionnaire is available at the website with permission for application, while the permission for the use of the questionnaire of emotional competence was acquired through personal communication with the author. Statistical processing of the participants' data was based on the SPSS programme. The first part of the quantitative research comprises basic descriptive statistics with analyses of the participants' demographic data, mean, standard deviations, participation shares. In the second part of the research we calculated the relation between degrees of emotional competence and stressful situations coping strategies. We checked the conditions for the calculation of the correlation coefficients (One-Sample Kolmogorov-Smirnov Test), applying Spearman's rho for the bivariate correlation analysis.

\section{Results}

\section{Descriptive Information}

The descriptive statistics data are presented in Table 1. They show the minimum, maximum and average number of points, standard deviation, skewness and kurtosis. 


\section{Correlation}

There is a positive correlation link between the competence Trust into the other's help and the Active coping strategy $(\mathrm{p}=0.002, \mathrm{r}=0.234)$, Use of instrumental support $(\mathrm{p}=0.000, \mathrm{r}=0.394)$, Positive reframing $(\mathrm{p}=0.001, \mathrm{r}=0.254)$ and Acceptance $(\mathrm{p}=0.02 \mathrm{O}, \mathrm{r}=0.181)$ is weak, while correlation link with the Use of emotional support $(\mathrm{p}=0.000, \mathrm{r}=0.411)$ is medium. There is a weak negative correlation link with Self-distraction $(p=0.003, r=0.232)$, Denial $(p=0.001, r=0.256)$, Selfblame ( $\mathrm{p}=0.001, \mathrm{r}=0.265)$, and medium correlation link with Behavioural disengagement $(\mathrm{p}=0.000, \mathrm{r}=0.427)$.

Positive correlation link between the competence Mutual cooperation between partners and Active coping $(\mathrm{p}=0.024, \mathrm{r}=0.175)$, Positive reframing $(\mathrm{p}=0.009, \mathrm{r}=0.203)$ and Acceptance $(\mathrm{p}=0.011, \mathrm{r}=0.197)$ is weak. Also weak and negative is the correlation link with Self-distraction $(\mathrm{p}=0.022, \mathrm{r}=0.177)$, Denial $(\mathrm{p}=0.017, \mathrm{r}=0.185)$, Behavioural disengagement $(\mathrm{p}=0.000, \mathrm{r}=0.331)$ and Selfblame $(\mathrm{p}=0.015, \mathrm{r}=0.189)$.

Correlation link between the competence Understanding plus verbal expression and Active coping $(\mathrm{p}=0.000, \mathrm{r}=0.284)$, Positive reframing $(\mathrm{p}=0.000$, $\mathrm{r}=0.299)$, Planning $(\mathrm{p}=0.003, \mathrm{r}=0.231)$, Humour $(\mathrm{p}=0.022, \mathrm{r}=0.178)$ and Acceptance $(\mathrm{p}=0.001, \mathrm{r}=0.262)$ is positive and weak. Self-distraction (po.009, $r=0.203)$, Denial ( $\mathrm{p}=0.000, \mathrm{r}=0.309)$ and Self-blame $(\mathrm{p}=0.001, \mathrm{r}=0.245)$ have a weak negative correlation. Behavioural disengagement $(\mathrm{p}=0.000, \mathrm{r}=0.409)$ has a medium negative link.

Correlation link between the competence Comparative emotional thinking and Active coping $(\mathrm{p}=0.048, \mathrm{r}=0.154)$, Planning $(\mathrm{p}=0.011, \mathrm{r}=0.196)$, Humour $(\mathrm{p}=0.025, \mathrm{r}=0.174)$ and Acceptance $(\mathrm{p}=0.001, \mathrm{r}=0.258)$ is weak positive. Weak negative is the link with Denial $(\mathrm{p}=0.045, \mathrm{r}=0.156)$.

The competence Emotional oscillations has a statistically significant weak negative correlation link with the strategies Denial $(\mathrm{p}=0.014, \mathrm{r}=0.190)$, Behavioural disengagement $(\mathrm{p}=0.006, \mathrm{r}=0.214)$ and Self-blame $(\mathrm{r}=0.196)$.

The competence Autonomous search of new options has a weak positive correlation with Religion ( $\mathrm{p}=0.000, \mathrm{r}=0.286)$ and Self-blame $(\mathrm{p}=0.000, \mathrm{r}=0.286)$ and a medium strong one with the subdimensions Planning $(\mathrm{p}=0.000, \mathrm{r}=0.357)$ and Acceptance $(\mathrm{p}=0.000,0.446)$, as well as a strong correlation with Positive reframing $(\mathrm{p}=0.000, \mathrm{r}=0.589)$. There is a weak negative correlation with the subdimension Denial $(\mathrm{p}=0.003, \mathrm{r}=0.233)$ and Self-blame $(\mathrm{p}=0.000, \mathrm{r}=0.286)$ and a medium one with Behavioural disengagement $(p=0.000, r=0.489)$.

The competence Autonomous wish for self-improvement has a weak positive link with Active coping $(\mathrm{p}=0.003, \mathrm{r}=0.227)$, Positive reframing $(\mathrm{p}=0.047$, $\mathrm{r}=0.155)$ and Religion $(\mathrm{p}=0.000, \mathrm{r}=0.290)$; it also has a moderate link with Plan$\operatorname{ning}(\mathrm{p}=0.000, \mathrm{r}=0.371)$. 


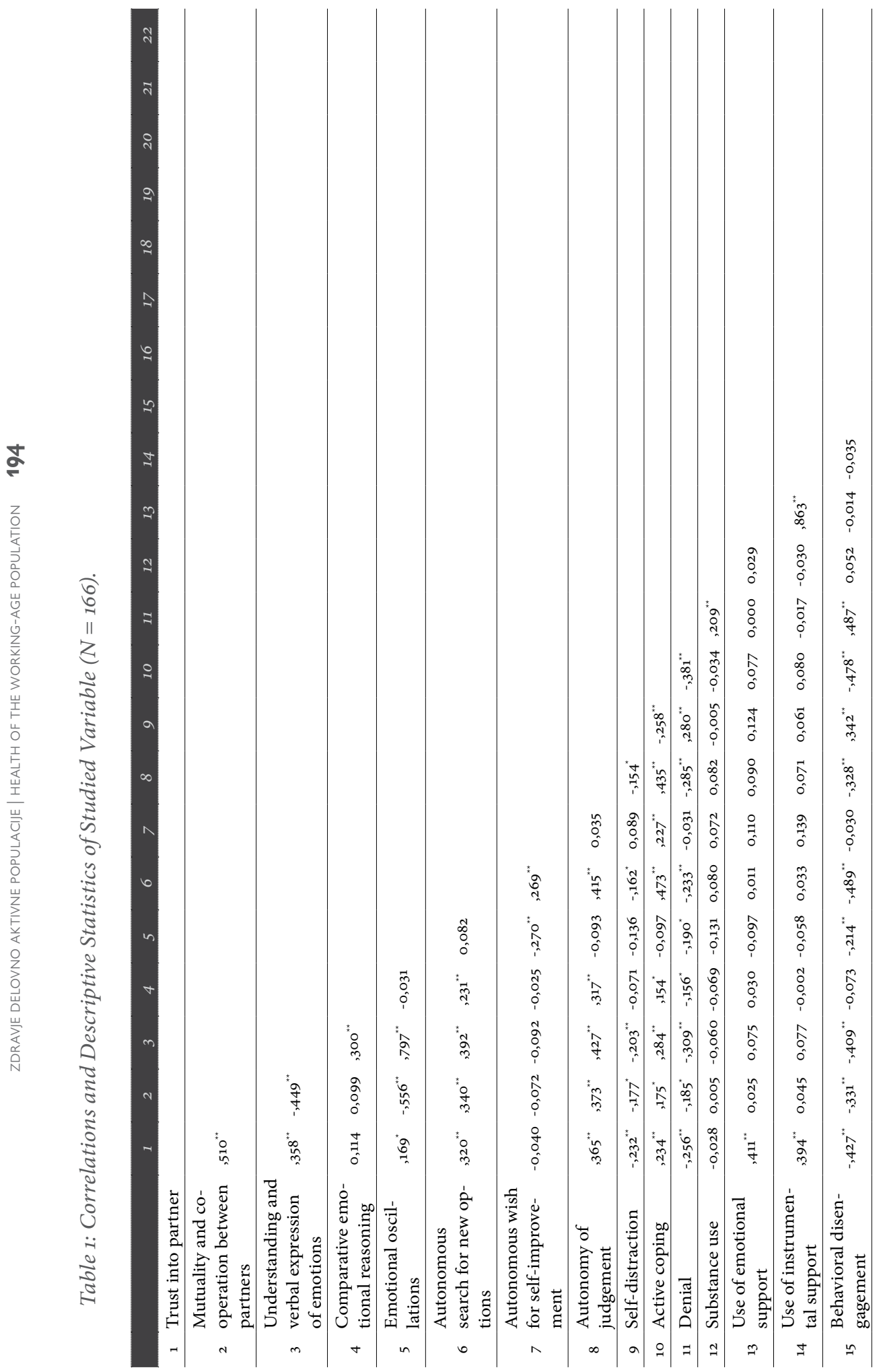




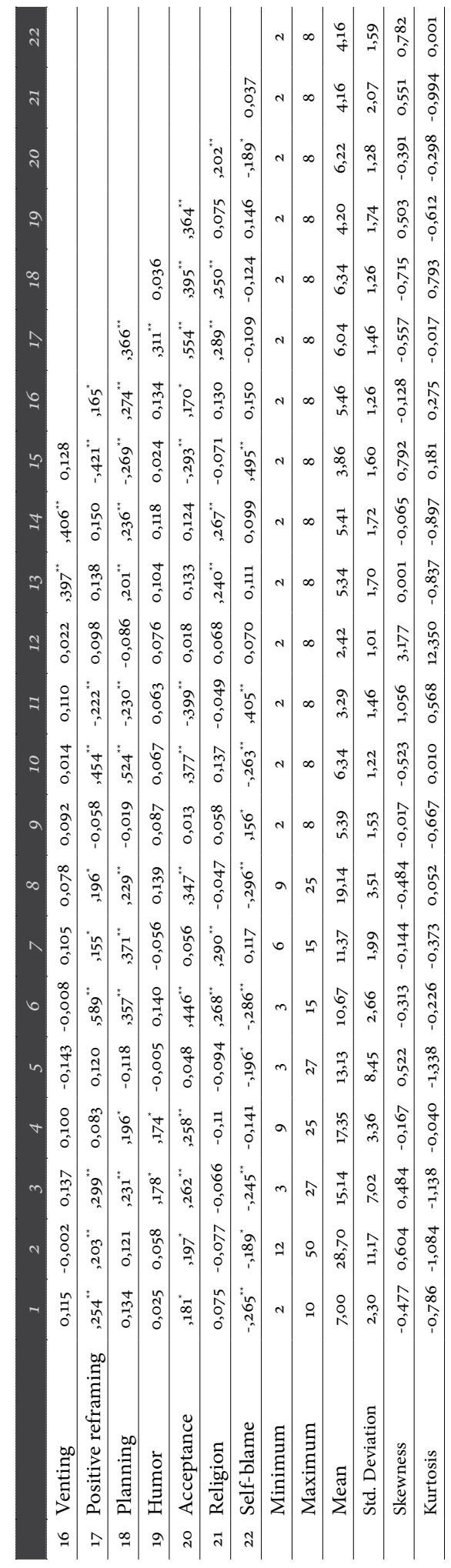

**. Correlation is significant at the o.or level

*. Correlation is significant at the 0.05 level

Weak positive link was shown by the results of the correlation between the competence Autonomy of judgement and strategies Positive reframing ( $\mathrm{p}=0.011, \mathrm{r}=0.196)$, Planning $(\mathrm{p}=0.003$, $r=0.229$ ), while the correlation with Active coping $(\mathrm{p}=0.000, \mathrm{r}=0.435)$ and Acceptance $(\mathrm{p}=0.000, \mathrm{r}=0.347)$ is moderate. There is a weak negative correlation with Self-distraction $(\mathrm{p}=0.047, \mathrm{r}=0.154)$, Denial $(p=0.000, r=0.285)$ and Selfblame ( $p=0.000 . r=0.286)$, and a moderate correlation with Behavioural disengagement $(\mathrm{p}=0.000, \mathrm{r}=0.328)$.

\section{Discussion}

According to the results, an individual that trusts into other people's help actively deals with problem solving in stressful situations, seeking help and emotional support with others. $\mathrm{He}$ is likely to perceive the problem from a positive point of view and to learn from the situation. He does not seek distraction in work and other activities to stop reflecting on the problem, neither does he deny it or despair. He does not blame or accuse himself for the situation. Mutual cooperation enables him to perceive the problem as a fact that can be dealt with.

Understanding, verbal expressing and comparative emotional thinking enable an individual - apart from actively confronting the problem - to develop a positive approach to problem, to plan solutions (also with humour), to accept them and live with them. He is thus less likely to distract himself with other activities (cinema, TV, reading, 
daydreaming, sleeping, shopping) so as to stop bothering about the problem. $\mathrm{He}$ is also less prone to denial and despair.

Individuals autonomously seeking new solutions and believing they can still make progress in the field of conflict management, individuals striving to improve their manner of reacting are the ones likely to see a problem from the positive and spiritual side, to plan solutions and live with them in a positive way; they are, however, also less likely to deny the problem and to despair.

Greater ability of autonomous judgement can be expected from persons actively dealing with problems, having a positive approach to problem solving, planning, accepting facts and learning from situations. Such persons are less likely to seek distraction elsewhere, to deny problems, despair and blame themselves.

Research studies dealing with correlation between emotional competence and stress do not exist. In the research study (Vater in Schröder Abé 2015) it has been ascertained that every factor of a personal characteristic is related to at least one strategy of emotional regulation. Emotional regulation, however, is the key factor in the development of emotional competence. According to the research study (Leger et al. 2016) on correlation between personal characteristics and stress differences between personal characteristics affect one's estimation of potential stressful situation. Interactional and transactional stress models guide much of this personality and stress-related research. These models propose that personality is associated with stress in the following ways. First, those with certain personality characteristics are more likely to expose themselves to more frequent and severe stressful experiences. Second, individual differences in personality traits may influence appraisals of potentially stressful circumstances. Last, personality is associated with the effectiveness of the coping responses whereby cognitive and behavioural efforts can prevent, manage, or alleviate distress. Results of this study indicate that personality traits are differentially associated with positive and negative stressor-related affect; neuroticism, conscientiousness and openness to experience uniquely contribute to the degree of stressor-related negative affect, and stressor-related appraisals partially account for this relationship. Only agreeableness relates to the degree of stressor-related positive affect, but how people appraise their daily stressors are unrelated to this association. These findings suggest that these differences in stressor-related affect may serve as one potential mechanism through which personality traits impact health and emphasize the need for future studies to examine not just changes in negative, but also changes in positive affect in response to stress.

\section{Conclusions}

People confront stressful situations in more or less functional ways. According to the present research project, emotional maturity and acquisition of emotional competences throughout individual's life affect the choice of his stress 
handling strategy. Emotional processing or, rather, the ability of emotional processing, is a new but ever more popular object of empirical research in psychotherapy, which is why it makes sense to determine in future, which are the key competences in individual work settings. Research studies will contribute to theoretical knowledge of emotional processes, serving as a basis for the creation of new therapeutic approaches, as well as for a more efficient clinical practice in the field of mental health.

\section{Limitations}

The research study has a few limitations. Research results cannot be compared to results of other research studies, as there are no research studies from the point of view of emotional competence

\section{References}

CARVER, CHARLES S., MICHAEL F. SCHEIER and JAGDISH K. WEINTRAUB. 1989. Assessing coping strategies: A theoretically based approach. Journal of Personality and Social Psychology 56, št. 2:267-283.

CVETEK, MATEJA. 2014. Živeti s čustvi: čustva, čustveno procesiranje in vseživljenski čustveni razvoj. V. Ljubljana: Teološka fakulteta.

GREENSPAN, STANLEY I. 1989. The development of the ego: Implications for personality theory, psychopathology, and the psychotherapeutic process. Madison, CT, US: International Universities Press, Inc.

LEGER, KATE A., SUSAN T. CHARLES, NICHOLAS A. TURIANO and DAVID M. ALMEIDA. 2016. Personality and stressor-related affect. Journal of Personality and Social Psychology 111, št. 6:917-928.

VATER, ALINE, and MICHELA SCHRÖDER ABÉ. 2015. Explaining the link between personality and relationship satisfaction: Emotion regulation and interpersonal behaviour in conflict discussions. European Journal of Personality 29, št. 2:201-215. 